\title{
DIAP: O LOBBYING DO TRABALHADOR NO CONGRESSO NACIONAL
}

\author{
Andréa Cristina de Jesus Oliveira \\ Doutora em Ciências Sociais (Unicamp), Docente do Departamento de \\ Ciências Jurídicas da Uninove (Centro Universitário Nove de Julho). \\ Responsável pelo Núcleo de Disciplinas Propedêuticas Gerais e Sociais.
}

\begin{abstract}
RESUMO
O presente texto teve como objetivo discutir as estratégias de ação utilizadas pelo DIAP (Departamento Intersindical de Assessoria Parlamentar), entidade que se auto intitula o lobby do trabalhador no Congresso Nacional. A história do DIAP está intrinsecamente relacionada ao processo de redemocratização pelo qual o país passou. Avaliamos, assim, a história de sua criação, ressaltando o processo de discussão e a articulação de interesses necessária para sua construção, assim como a estrutura e organização da entidade, seus objetivos, forma de atuação e principalmente as estratégias de ação colocadas em prática a fim de representar os interesses consensuais e majoritários de seus filiados.

Palavras-Chave: Lobbying. Representação de Interesses. Processo Legislativo. Grupos de pressão.
\end{abstract}

\section{Abstract}

This paper evaluates the strategies of action used by DIAP (Intersindical Department of Parliamentary Consultantship), the worker's lobby in the National Congress. The history of DIAP is deeply related to the redemocratization of the country. We evaluated the history of its creation, emphasizing the discussion process and the needed articulation of interests for its construction, as well as the structure and organization of the entity, their objectives, form of performance and mainly, the strategies of action put in practice in order to represent the consensual and majority interests of yours adopted.

Key-Words: Lobbying. Interests Representation. Legislative Process. Pressure Groups.

\section{Introdução}

As idéias aqui apresentadas são resultados de uma discussão mais ampla sobre o funcionamento do lobbying no Brasil e a atuação lobista em esfera federal, contida na tese de doutorado intitulada Lobby e Representação de Interesses: lobistas e seu impacto na representação de interesses no Brasil.

Nosso trabalho de campo assumiu as características de uma pesquisa qualitativa combinando pesquisa documental, bibliográfica e um trabalho etnográfico. A escolha de um trabalho etnográfico, realizado por observação 
direta e indireta, justifica-se pela própria natureza do lobbying, que, no Brasil é tido como ilegal ou visto meramente como tráfico de influência e corrupção. Os dados apresentados foram fruto da análise das entrevistas e de material coletado na entidade classista em questão. Ao todo, foram empreendidas cinco entrevistas, coleta e análise de material coletado na entidade classista, além de pesquisa bibliográfica.

A atividade lobista apresenta uma grande diversidade de formatos e para analisá-la nós a caracterizamos em quatro tipos: a) lobbying público: assessorias de assuntos parlamentares ou Departamentos de Comunicação Social dos Ministérios, Agências Reguladoras e Autarquias; b) lobbying institucional: executivos de relações governamentais, alocados em departamentos de assuntos corporativos/institucionais das empresas da iniciativa privada; c) lobbying classista: entidades classistas, como a CNI (Confederação Nacional da Indústria) e o DIAP (Departamento Intersindical de Assessoria Parlamentar) e d) lobbying privado: escritórios de consultoria e lobbying.

Lobbying é o processo pelo qual os grupos de pressão buscam participar do processo estatal de tomada de decisões, contribuindo para a elaboração das políticas públicas de cada país.

Em uma sociedade democrática, os tomadores de decisão são confrontados com uma complexa rede de interesses e se valem das idéias e opiniões dos grupos de pressão para subsidiarem suas decisões. Os grupos de pressão fornecem informações confiáveis e comprováveis aos tomadores de decisão e os mesmos transformam esses grupos em interlocutores, convidando-os a emitir sua opinião quando necessário.

A atividade inclui a coleta de informações, propostas políticas, estratégias apropriadas para dar suporte a tais demandas, confecção de pesquisas e a procura por aliados. O lobbying proporciona a troca de informações e de idéias entre governo e partes privadas, capazes de infundir nas políticas públicas conhecimento de causa e realismo consciente. Seu último estágio é a pressão, momento em que o lobista deve se valer de seu poder de comunicação e persuasão (GRAZIANO, 1996).

Sendo assim, podemos conceber o lobbying como saber especializado e representação técnica, pois enquanto representam interesses especiais, os lobistas são o sustentáculo da informação de um especialista técnico-político.

Esse tipo de saber específico ajuda os tomadores de decisão a formular propostas políticas e a perceber as reações da sociedade civil frente a essas propostas.

O presente texto tem como objetivo discutir as estratégias de ação utilizadas pelo DIAP, já que a atuação da entidade nos chamou a atenção por seu caráter propositivo e forte presença junto ao Poder Legislativo federal. 


\section{História do DIAP}

Segundo Aragão (1992), o retorno dos trabalhadores ao Congresso Nacional se deu em três etapas. A primeira delas, com a presença de representantes credenciados perante a Câmara dos Deputados, para fins de monitoramento e assessoria, na segunda metade dos anos 70. Em 1977, a CONTAG, a Confederação Nacional dos Trabalhadores em Comunicação e Publicidade e a FENCAVIR (Federação Nacional dos Condutores Autônomos de Veículos Rodoviários) encontravam-se credenciados junto à Câmara dos Deputados.

A segunda etapa deu-se com a criação do Partido dos Trabalhadores. A decisão de criar o PT nasceu da constatação de que os trabalhadores não estavam efetivamente representados no Congresso Nacional. Havia total desarticulação das lideranças de trabalhadores com as lideranças políticas do Legislativo.

A terceira etapa ocorreu ao largo das intensas polêmicas sobre quem exerceria a hegemonia das lideranças sindicais, com a criação em 1983 do DIAP (Departamento Intersindical de Assessoria Parlamentar), como resposta à intensificação das ações dos grupos de pressão de natureza empresarial no Congresso.

O DIAP tem como objetivo atuar junto aos Poderes Legislativo e Executivo, sobretudo no poder Legislativo e, excepcionalmente, junto às Assembléias Legislativas e Câmaras de Vereadores, a fim de representar e defender os interesses consensuais da classe trabalhadora.

É um instrumento dos trabalhadores que foi idealizado pelo advogado trabalhista Ulisses Riedel de Resende, atual Diretor-Técnico da entidade.

A idéia sobre a criação do DIAP está intrinsecamente relacionada à experiência de Ulisses Riedel e surge em 1968, quando o mesmo foi convidado pelo governo norte-americano a conhecer, juntamente com mais cinco advogados brasileiros, sua organização sindical. Em Washington, visitaram a AFL-CIO ${ }^{1}$.

Segundo Ulisses Riedel ${ }^{2}$, dois departamentos da AFL-CIO chamaram sua atenção. $O$ primeiro tinha como objetivo arrecadar recursos para o financiamento de campanhas, e o segundo era o Departamento Legislativo, que era responsável pelas questões legislativas.

Esse departamento pareceu-lhe extremamente interessante, pois estava encarregado de acompanhar projetos de lei no Congresso Nacional, oferecendo

\footnotetext{
${ }^{1}$ A AFL-CIO é a American Federation of Labor and Congress of Industrial Organizations, que congrega 13 milhões de trabalhadores. É a maior central sindical norte americana. Informações obtidas em 2004 pelo site oficial da entidade: www.aflcio.org.

${ }^{2}$ Entrevista com Ulisses Riedel em 08/08/2003.
} 
subsídios, defendendo posições, informando aos parlamentares as expectativas dos trabalhadores, informando aos trabalhadores a atuação parlamentar e dando notas aos parlamentares pela sua atuação, a favor, ou contra os trabalhadores. Além dessas tarefas, o Departamento Legislativo ainda identificava as reivindicações dos trabalhadores, preparava projetos e encaminhava esses projetos, através de parlamentares, para o Congresso Nacional. Era sua atribuição elaborar projetos para que os parlamentares os apresentassem.

Com o desenrolar dos debates, eram preparadas emendas e havia então o acompanhamento da tramitação do projeto. Logo em seguida, o processo de pressão tinha início. O departamento, através de seus lobistas, pressionava os parlamentares a votar a favor ou contra determinado projeto.

As condições políticas para a criação de um órgão com as mesmas atribuições do Departamento Legislativo da AFL-CIO eram desfavoráveis e a idéia teve que aguardar o início do processo de redemocratização do país.

Segundo Ulisses Riedel, a criação de um departamento como esse seria um caminho democrático muito interessante, que fomentaria uma mudança da situação social de uma forma democrática, pois seria possível acompanhar a atuação dos parlamentares e seria possível também mostrar a eles as demandas dos trabalhadores, podendo assim instrumentalizá-los com informações. Seria possível levar informação aos parlamentares e aos trabalhadores ao mesmo tempo.

Quando o processo de abertura democrática foi deflagrado, Ulisses Riedel já era advogado de uma centena de entidades sindicais e, entre elas, 7 das 9 confederações de trabalhadores que existiam no período. Ele tinha um número gigantesco de processos nos tribunais e contava com um relacionamento muito próximo a todas as lideranças sindicais.

O atual Diretor Técnico do DIAP começou a disseminar sua idéia nas conversas com os dirigentes sindicais. Em uma dessas conversas, o dirigente sindical, Comandante Aloísio Ribeiro - um dos diretores da CONTTMAF (Confederação Nacional dos Trabalhadores em transportes marítimos, aéreos e fluviais) - se interessou pela idéia e resolveu apoiá-la.

No I Congresso Nacional de Estivadores, Portuários, Marítimos, Fluviários, Aeroviários, Aeronautas e Pescadores, em agosto de 1981 em Fortaleza/CE, a idéia sobre a criação do DIAP, já esboçada por Ulisses Riedel, foi levada para votação e aprovada.

O que se aprovara era o esboço de um órgão suprapartidário, desvinculado de qualquer corrente ideológica, partidária ou religiosa, mas comprometido com a defesa dos trabalhadores e comprometido em bem informá-los e também aos parlamentares. A partir dessa primeira aprovação, Ulisses Riedel pode levar sua idéia sobre a criação do DIAP a outras entidades, legitimado pela 
aprovação de uma confederação nacional.

Em 1983, com o apoio da CONTAG (Confederação Nacional dos Trabalhadores na Agricultura), foi realizada uma primeira reunião, em sua sede, objetivando a criação do DIAP, convocada pela CONTTMAF, contando com a presença de 17 entidades. Nessa reunião, o representante da FANJ (Federação Nacional dos Jornalistas), Armando Rollemberg, sugeriu que os sindicatos presentes à reunião se transformassem na comissão organizadora do DIAP, fazendo em conjunto uma nova convocação, buscando a participação de um maior número de entidades. A sugestão foi aprovada e uma nova reunião foi agendada.

Em 19/12/1983, ocorreu a fundação do Departamento Intersindical de Assessoria Parlamentar (DIAP), na sede da Confederação Nacional dos Trabalhadores na Agricultura (CONTAG), em Brasília/DF.

Integraram a Comissão Organizadora do Departamento as seguintes entidades: Confederação Nacional dos Trabalhadores em Transportes Marítimos, Fluviais e Aéreos (CONTTMAF), Confederação Nacional das Profissões Liberais (CNPL), Federação Nacional dos Trabalhadores nas Indústrias Urbanas, Federação Nacional dos Estivadores, Federação Nacional dos Trabalhadores em Empresas de Telecomunicações e Operadores de Mesa Telefônica e o advogado Ulisses Riedel.

Estavam presentes na primeira Assembléia 51 entidades sindicais de todo o país, que aprovaram os Estatutos, elegeram e deram posse à primeira diretoria, além de definir a contribuição das entidades associadas.

O modelo estrutural do DIAP foi inspirado no do DIEESE (Departamento Intersindical de Estatísticas e Estudos Sócio-Econômicos), fundado em São Paulo em 1955, com um corpo diretivo composto de dirigentes dos sindicatos filiados e uma Diretoria Técnica. Segundo Santos (1998), enquanto a atuação do DIEESE se desenvolveu no âmbito técnico e científico, sem engajamento político direto, o DIAP tomou o caminho político, atuando como lobby.

De acordo com Figueira (1987),

Com o DIAP, os trabalhadores brasileiros seguem a trilha da AFL/CIO norteamericana, que congrega mais de 100 sindicatos nacionais - de professores a bombeiros hidráulicos e funcionários públicos - com 15 milhões de associados, que dispõe de um departamento parlamentar ocupando um prédio inteiro a dois quarteirões da Casa Branca - um império onde reinam oito lobistas assistidos por 15 especialistas com curso superior (engenheiros, advogados, economistas, administradores), sete ex-deputados e ex-senadores e centenas de secretárias, datilógrafas e arquivistas que desenvolvem atividades que compreendem desde a elaboração de projetos de lei até o levantamento de fundos para campanhas políticas. 


\section{O DIAP e a Assembléia Nacional Constituinte}

O DIAP apresentou um desempenho excelente durante os trabalhos da Assembléia Nacional Constituinte e foi justamente nesse momento que seu trabalhou ganhou visibilidade e credibilidade (DREIFUSS, 1989).

Porém, os anos que antecederam a instalação da Assembléia Nacional Constituinte também foram marcados por muito trabalho.

Em 1984, as atividades mais importantes do DIAP foram a elaboração do Projeto Um - que congregava as bandeiras e lutas do movimento sindical - como a aprovação de anteprojeto de lei que proibia a demissão imotivada, e o lançamento do Jornal do DIAP, primeiro órgão de comunicação do Departamento, enviado para as entidades sindicais de todo país.

1985 foi tomado por discussões sobre os projetos Dois e Três do DIAP. O projeto Dois versava sobre o Poder Normativo da Justiça do Trabalho e o projeto Três, sobre a Organização Sindical.

Em 1986, além das discussões sobre a aprovação de Projeto de Lei sobre demissão imotivada, Assembléia Nacional Constituinte, jornada de trabalho de 40 horas e paridade entre trabalhador aposentado e ativo, houve o lançamento do livro Quem é Quem do DIAP, que examinou a atuação parlamentar dos deputados federais da Legislatura 1983/1987.

Com a instalação da Assembléia Nacional Constituinte em $1^{\circ}$ de fevereiro de 1987, todos os esforços do DIAP estiveram voltados para ela. Nesse período, eles apresentaram uma Emenda Popular sobre os Direitos dos Trabalhadores e participaram ativamente do Centro de Estudos e Acompanhamento da Constituinte (CEAC/UNB). Foi a partir das experiências observadas pelo CEAC/UNB que o DIAP ajudou a criar, o livro Cidadão Constituinte: a saga das emendas populares (MICHILES et al., 1989).

O amplo movimento de "Participação Popular na Constituinte", atuante durante todo o processo constituinte, elaborou emendas populares à Constituição e coletou subscrições em todo o país, marcando um momento de inflexão no qual práticas predominantemente reivindicativas, de ação direta ou "de rua", foram substituídas por propostas políticas mais elaboradas e levadas aos canais institucionais conquistados, como a própria iniciativa popular de lei que permitiu as emendas constituintes (CARVALHO, 1998).

A fim de reunir um maior número possível de entidades, associações, sindicatos, movimentos populares, fóruns, plenários e outras formas de pressão social na Constituinte, foi criada a Articulação Nacional de Entidades pela Mobilização Popular na Constituinte, do qual o DIAP também fazia parte. Era necessário mobilizar a população para se garantir o somatório de 30 mil assinaturas necessárias por emenda popular. No entanto, os movimentos populares enfrentavam dois problemas: por um lado, o peso do 
ceticismo e apatia da sociedade brasileira; por outro, as inevitáveis divergências de enfoque sobre os posicionamentos a se tomar diante da Constituinte (MICHILES et al., 1989).

O primeiro documento extraído dessa Articulação, em 28 de maio de 1987, visando sua consolidação continha algumas deliberações provenientes de reunião conjunta dos comitês populares de defesa da Constituinte e dos plenários pró-participação popular na Constituinte.

Os objetivos eram: intensificar a mobilização do povo e unificar a coleta de assinaturas para as propostas de emendas populares, assegurando um amplo movimento de apoio às reivindicações populares dirigidas à Constituinte; necessidade urgente de unificar os esforços das entidades para preparar um lançamento da campanha nacional de apoio às emendas populares; instituir o Dia Nacional de Mobilização para coleta de assinaturas (17 de julho), com realização de atividades para arrecadar assinaturas, atos públicos, debates, comícios, shows, em cada estado e município; realizar entrega conjunta e unitária de caráter nacional dos milhões de assinaturas coletadas relativas às emendas de iniciativa popular.

Formou-se uma Comissão Executiva, necessária para implementar as decisões da Articulação e recorreu-se ao CEAC/UNB para as tarefas de secretaria nacional.

No entanto, havia problemas e estes provinham, sobretudo, da diversidade das entidades e movimentos que o compunham - muitos dos quais, absorvidos em práticas e prioridades paralelas, tentaram carrear para dentro desse "fórum" preocupações, sem dúvida legítimas, mas que não se ajustavam à natureza da Articulação. Apontavam-se falhas devido à improvisação organizativa e falta de direção política.

O acompanhamento do desempenho parlamentar foi encarado como um instrumento de luta da Articulação.

Para que esse mecanismo de pressão chegasse a funcionar razoavelmente, atingindo as bases eleitorais do constituinte-alvo, todo um sistema de comunicação rápido e fidedigno teria de ser construído com os próprios recursos dos movimentos sociais. Os organismos de assessoria parlamentar como o DIAP e o INESC (Instituto de Estudo Sócio-Econômicos), com os quais os setores populares se identificavam, possuíam um quadro limitado de especialistas, montado para cobrir aqueles temas que justificavam a razão de sua existência.

Entre as garantias de participação da sociedade civil reguladas no regimento interno da Assembléia Nacional Constituinte estava a exigência de, no mínimo, três entidades responsáveis pelo encaminhamento de uma emenda. 
O trabalho do DIAP se estendeu desde a elaboração da emenda popular sobre os direitos do trabalhador, até o acompanhamento de sua tramitação, passo a passo, na comissão pertinente.

Nesse período, o DIAP chegou a publicar uma cartilha intitulada: "Como atuar no Congresso”. Essa cartilha contava com algumas recomendações, como por exemplo: cabia aos representantes das entidades classistas observar o quórum das comissões. Se observasse que a maioria era precária, seria necessário orientar os suplentes alinhados à causa dos trabalhadores para que assinassem o livro de presença em primeiro lugar. Assim, na eventualidade de faltar alguém do grupo conservador, haveria um progressista lá para garantir o voto. Nessa cartilha, havia ainda mais uma série de táticas e recomendações que foram passadas às entidades classistas e que acabaram dando resultado.

Segundo Santos (1998), Quem foi Quem na Constituinte, publicação do DIAP, que sistematizou uma pesquisa que registrou a atuação de cada um dos 573 parlamentares durante o processo de elaboração da Constituição de 1988, foi um dos instrumentos de ação que marcaram época, porque pôs na mão dos trabalhadores um critério permitindo "julgar" os representantes, recomendá-los ou contra-indicá-los ao voto popular em futuras eleições.

Na época da publicação de Quem foi Quem, o DIAP possuía cerca de 431 entidades filiadas e sua atuação ainda não havia conquistado total confiança por parte do movimento sindical. Concluídos os trabalhos da Constituinte e publicado o livro "Quem foi Quem", o DIAP alcançou grande visibilidade pública e conquistou a legitimidade do movimento sindical, que passou a vê-lo como um órgão de assessoria, por excelência (DIAP, 1988).

Santos (1998, p. 325), sobre a importância do DIAP no período constituinte, afirma que,

Entre outras realizações, devem creditar-se boa parte ao DIAP, já assessor da CUT e da CGT à época, a formulação inicial do que viria a ser o capítulo dos Direitos Sociais e outras vantagens dos trabalhadores na Constituição de 1988. É, porém, questionável que o detalhismo utilizado desde o ante-projeto inicial haja representado uma conquista de longo prazo. É plausível a hipótese de que, ao petrificar fórmulas tão minuciosas, tenha contribuído largamente para motivar as reações corporificadas, a curto prazo, no surgimento do Centrão e a longo prazo nas sucessivas e incansáveis tentativas de mudança de texto constitucional.

Segundo Aragão (1992), a atuação do DIAP foi bastante intensa desde sua criação, reunindo lideranças sindicais adversárias, mas obtendo apoio para trabalhar pela consecução de conquistas para os trabalhadores, culminando com os resultados significativos alcançados no processo constituinte, como apresentado. 


\section{Estrutura e organização do DIAP}

O DIAP é constituído por cerca de 900 entidades sindicais de trabalhadores, congregando Centrais, Confederações, Sindicatos e Associações, distribuídas em todos os estados e territórios do país, das quais 90 estão alocadas em Brasília.

Apesar de reunir lideranças sindicais adversárias, o DIAP se estrutura a partir de uma postura apartidária, pluripartidária e suprapartidária, a fim de que seu trabalho não contribua para reforçar ainda mais as idiossincrasias de cada entidade representada. Desse modo, o DIAP só defende e representa matérias consensuais no movimento sindical, as quais representem o seu pensamento majoritário.

O comando político-sindical do DIAP é exercido pelas entidades filiadas, que constituem a Assembléia Geral, e se reúnem periodicamente. Já a sua Diretoria é constituída por dirigentes sindicais, portanto, as decisões democráticas tendem a ser uma realidade.

O DIAP possui uma Diretoria Técnica e uma Diretoria Executiva. É atribuição da Diretoria Técnica coordenar as reuniões de técnicos e consultores, a emissão de pareceres, o controle de projetos, a atuação sobre os parlamentares e a informação e orientação às entidades sindicais. Além da Diretoria Técnica e da Diretoria Executiva, há uma equipe de dez assessores permanentes que cuidam da elaboração dos boletins, jornais e outras publicações, e também uma rede de colaboradores em todo o Brasil constituída por advogados com atividade bastante significativa no movimento sindical e que contribuem com suas análises para o trabalho do DIAP.

A fonte dos recursos financeiros do DIAP advém exclusivamente da contribuição de seus filiados. Para viabilizar suas publicações, busca parcerias com as entidades. Seu orçamento mensal é de $\mathrm{R} \$ 30.000,00$ por mês.

\section{Forma de atuação do DIAP}

Para representar os interesses consensuais do movimento sindical brasileiro, o DIAP adota uma forma de atuação que consiste em elaborar estudos e projetos de lei, monitorar projetos e estudos, emitir pareceres sobre projetos e estudos apresentados; credenciar pessoas habilitadas a atuar junto a órgãos e instituições públicas e privadas, e manter publicação periódica sobre a atuação do Congresso Nacional (FIGUEIRA, 1987).

\section{Monitoramento Legislativo}

O monitoramento legislativo consiste no acompanhamento detalhado da tramitação das matérias apresentadas, debatidas e votadas no Congresso Nacional. 
O número de projetos acompanhados é enorme, pois são monitorados todos os projetos que possam apresentar riscos ou oportunidades aos trabalhadores assalariados. Projetos que defendam a criação ou a exclusão de direitos dos trabalhadores assalariados são classificados como projetos que apresentam riscos ou oportunidades. Assim como monitora e acompanha o trabalho legislativo, o DIAP informa aos sindicatos de trabalhadores e à sociedade civil os desdobramentos desses projetos.

Em suma, o monitoramento legislativo conta com uma matriz de acompanhamento, na qual encontram-se o número do projeto, o autor, o resumo do projeto, a situação em que ele se encontra no Congresso, quais os próximos passos que ele vai percorrer e quais as tendências, de aprovação ou rejeição.

\section{Cenário Político}

A construção do cenário político consiste na análise da conjuntura política e do timming das votações empreendidas no Congresso Nacional.

A análise de cenário político requer um grande montante de informações que podem ser obtidas através dos meios de comunicação de massa e fontes, como jornalistas, assessores parlamentares, presidentes de comissões, outros profissionais da área de representação de interesses e os próprios parlamentares.

A análise de cenário político é importante, pois situa a discussão sobre determinado projeto em um horizonte mais amplo. É através da análise de cenário político que se determina, de pronto, quem são os atores envolvidos em determinada discussão e se formulam tendências que serão úteis para a construção da estratégia de ação.

É nesse momento que se avaliam as possibilidades de aprovação do projeto proposto, o que pode poupar muito esforço e trabalho.

\section{Monitoramento Político}

O monitoramento político consiste na identificação do perfil do parlamentar. Os candidatos são investigados anteriormente à posse, desde as eleições. São investigadas as seguintes questões: informações gerais sobre o candidato, origem, financiamento de campanha e posição ideológica sobre as questões de interesse dos trabalhadores.

Depois de eleito e empossado, uma nova investigação é efetuada a fim de identificar sua posição ideológica a respeito dos temas que serão discutidos naquela legislatura.

O monitoramento político instrumentaliza a avaliação que identifica a posição dos tomadores de decisão sobre os interesses dos trabalhadores. Com 
essa análise, é possível articular alianças e identificar interesses contrários aos defendidos pelo DIAP.

A partir do monitoramento político é efetuada a identificação dos líderes ou parlamentares mais influentes no Congresso Nacional. Essa pesquisa dá origem a uma das mais importantes publicações do DIAP, intitulada: Os "Cabeças" do Congresso Nacional. O DIAP complementa as informações coletadas a partir dos dados do monitoramento político e da investigação sobre a posição ideológica do parlamentar, observando a atuação dos mesmos no Congresso Nacional. São combinadas ainda informações qualitativas e quantitativas sobre os parlamentares. Para isso, são ouvidos outros parlamentares, cientistas políticos e funcionários do Congresso Nacional.

A série "Os Cabeças do Congresso Nacional" começou a ser editada em 1993 e reúne os 100 parlamentares mais influentes do Poder Legislativo. Seu objetivo é fornecer ao movimento sindical uma radiografia dos principais interlocutores - partidários, profissionais, ideológicos ou de grupos políticos - no Congresso Nacional, publicando um rápido perfil com resumo das principais habilidades dos parlamentares que realmente exercem influência no processo decisório do Poder Legislativo. Os parlamentares são classificados em cinco categorias: a) debatedores; b) articuladores/organizadores; c) formuladores; d) negociadores e e) formadores de opinião. Essas categorias não são excludentes entre si.

\section{Estratégia de Ação}

Há dois tipos de estratégias de ação formuladas pelo DIAP. A primeira é direcionada a pleitos específicos das entidades e a segunda é direcionada a pleitos que representam o pensamento consensual do movimento sindical.

Essa diferenciação entre as estratégias de ação ocorre porque o DIAP não atua diretamente em causas específicas das entidades. Ele apenas as orienta a agir.

Se o interesse da entidade é específico, o DIAP empreende uma análise com sentido estratégico, direcionada para a entidade em questão, no sentido de fazer com que dentro daquela conjuntura se criem condições para que se viabilize o pleito da entidade. É traçada uma estratégia de ação e fornecida orientação adequada para a entidade. Assim, a equipe técnica do DIAP fornece informações, estudos e orienta as entidades a agir. Porém, são elas quem fazem o corpo-a-corpo para a defesa e representação de seus interesses.

O DIAP também ministra cursos de treinamento em processo legislativo para os dirigentes das entidades, a fim de instrumentalizá-los para o trabalho de corpo-a-corpo.

O treinamento à equipe das entidades é necessário, pois o processo 
legislativo é razoavelmente complexo. É impossível traçar uma estratégia de corpo-a-corpo no Congresso Nacional sem conhecer os meandros de seu funcionamento e os princípios básicos do processo legislativo. Sem esse conhecimento, o dirigente da entidade classista pode facilmente se enganar ou ser enganado.

O Diretor de Documentação do DIAP reafirma essa posição do departamento, ao afirmar que,

A nossa orientação é para que as entidades atuem junto aos parlamentares para que se corrija esse ponto, aperfeiçoe aquele outro, sob pena das entidades irem a campo, atuarem e derrotarem o governo nesse particular. Quem faz o corpo-acorpo são as entidades. Porque aí, nesses casos, como as entidades têm interesses divergentes, como por exemplo: os servidores estaduais e municipais se preocupam com os sub-tetos e os federais não se interessam por isso. Paridade e integralidade são temas que interessam a todos. Contribuição dos inativos interessa a quem está próximo a se aposentar ou está aposentado. Então, as entidades atuam conforme suas particularidades. O que fazemos é mostrar o caminho, as pessoas é que decidem. Mostramos o momento mais oportuno, onde as chances se ampliam, que tipo de ação desse ser feita para alcançar o objetivo desejado.

As estratégias de ação formuladas pelo DIAP não se resumem à elaboração de estudos técnicos e à orientação de como efetuar o corpo-a-corpo. Dependendo do interesse a ser defendido, o DIAP orienta as entidades a promover grandes mobilizações populares, pois essas mobilizações dão aos parlamentares e ao governo a dimensão de que há resistência a determinada proposta e de que essa proposta não coincide com o que foi sufragado nas urnas, além de levar o debate para a esfera pública.

Um bom exemplo de mobilização levado a cabo pelas entidades foi o que ocorreu durante os debates sobre a Reforma da Previdência. Cerca de 70 mil pessoas protestaram contra a proposta apresentada pelo poder Executivo na Esplanada dos Ministérios, e o DIAP, mais uma vez, esteve a frente desse processo.

Enquanto os trabalhadores protestavam contra a proposta do poder Executivo, um forte trabalho de corpo-a-corpo era empreendido por dirigentes de entidades classistas e também pelo Diretor de Documentação do DIAP sobre os parlamentares, que se encontravam negociando soluções para diversos impasses acerca da Reforma da Previdência.

No trabalho de corpo-a-corpo, as entidades costumam se valer das informações técnicas fornecidas pelo DIAP, transformando-as em slogan político. Esse slogan político pode ser prejudicial à campanha de reeleição de qualquer candidato. Eis aqui um grande instrumento de convencimento.

Cerca de $10 \%$ das entidades filiadas, ou seja, 90 entidades, possuem 
sede em Brasília e atuam ostensivamente no Congresso Nacional, pois o consideram uma instância importante para formular as políticas públicas de interesse dos trabalhadores. Essas entidades possuem uma relação bastante estreita com o DIAP e costumam apoiá-lo na defesa das matérias consensuais do movimento sindical.

Apesar de orientar a ação das entidades filiadas na representação e defesa de seus interesses específicos junto ao Congresso, o foco principal do DIAP é a atuação sobre as matérias consensuais do movimento sindical e que representam o pensamento majoritário de todas as entidades representadas, que ao todo são 900 .

O pensamento majoritário das entidades filiadas é captado através dos Encontros Anuais do DIAP, e também de seminários sobre assuntos específicos que o DIAP organiza. Além disso, a própria diretoria do DIAP é composta por dirigentes de diversas entidades, os quais exprimem sua opinião sobre as questões que estão sendo discutidas no momento.

Segundo o Diretor de Documentação do DIAP,

O DIAP tem alguns princípios de atuação e sempre atua de forma unitária no movimento sindical. Na época da fundação, todas as entidades trabalhadoras nos subscreveram uma autorização para que pudéssemos atuar em nome delas. Podemos atuar em assuntos que são consensuais. Por exemplo: nós não entramos na discussão sobre unicidade e pluralidade do movimento sindical. Esse tipo de matéria divide o movimento sindical. A gente atua em bases técnicas, sobre temas absolutamente consensuais. Nós não entramos nessas 'bolas de dividir'.

Desse modo, quando há interesses consensuais em jogo, o Diretor de Documentação do DIAP traça a estratégia de ação e faz a intervenção política, ou seja, o corpo-a-corpo.

Diferentemente da CNI, o DIAP e as entidades filiadas continuam a atuar quando o projeto vai ao plenário. Nesse momento, eles estão munidos de um diagnóstico sobre o pensamento dos parlamentares a respeito do projeto, de uma análise técnica ponto a ponto do projeto e de uma avaliação sobre as chances positivas ou negativas de reverter o quadro apresentado.

Quando se começa a votar as particularidades do projeto, surge a figura do destaque em separado, que é apresentado antes do início da votação, e é exatamente nesse momento que o DIAP e as entidades filiadas começam a negociar com os parlamentares.

Podemos perceber que a negociação em plenário não só não é deixada de lado, como faz parte da estratégia de ação política do DIAP. O importante é convencer, não importa o momento. Se for preciso barganhar para que os interesses dos trabalhadores sejam defendidos, o DIAP o fará. 
Outra estratégia de ação política interessante é descrita por seu Diretor de Documentação:

Ainda com relação às estratégias, além das publicações, temos as análises semanais do quadro e mantemos contato permanente com os parlamentares, no sentido de adverti-los quanto a erros e desvios de condução, mostrando a importância, a necessidade e a conveniência do pleito da entidade e que um enfrentamento, além de trazer desgaste para o governo e para a própria base parlamentar, não atinge os objetivos que eles imaginam atingir com essas mudanças. Então se faz algum trabalho de convencimento também.

A afirmação acima deixa ver que o convencimento técnico é orientado sempre no sentido de chamar a atenção para a inconsistência da matéria em análise, deixando essa inconsistência clara para o parlamentar.

As publicações do DIAP são essenciais no processo de convencimento do parlamentar, uma vez que, além de apontar a opinião do movimento sindical, avalia a atuação dos parlamentares e as divulga.

As notas atribuídas pelo DIAP aos parlamentares são utilizadas como referência pelas entidades e pela sociedade civil. Normalmente causam polêmica quando publicadas, como foi o caso da publicação Quem foi Quem na Constituinte.

A atuação dos parlamentares é avaliada segundo as matérias de interesse dos trabalhadores assalariados e que acarretem alguma perda aos mesmos.

Os parlamentares que votam contra esse dado projeto sabem que sua atuação está sendo monitorada pelo DIAP e que ele a divulgará a todas as suas entidades filiadas e à sociedade civil.

Ao ser extremamente criterioso no trato das informações coletadas, o DIAP alcançou visibilidade e credibilidade. No trabalho de corpo-a-corpo, ou seja, de influência e convencimento, a visibilidade e credibilidade do DIAP são seus grandes trunfos.

\section{Publicações do DIAP}

O DIAP tem um apreço especial por suas publicações. Elas são fontes de referência para qualquer cidadão que queira compreender o funcionamento do processo legislativo brasileiro es sobretudo, que queira entender as demandas e a atuação política do movimento sindical no âmbito federal. Apesar de trabalhar com escassos recursos financeiros e com uma pequena equipe de técnicos, o DIAP veicula uma grande quantidade de informações.

Além da correspondência que mantém com seus filiados, o DIAP edita regularmente o Boletim Informativo e o Jornal do DIAP; estes distribuídos a 8.000 entidades sindicais de trabalhadores, aos senadores, deputados, ór- 
gãos governamentais e à grande imprensa em Brasília. O material do DIAP é multiplicado pela imprensa sindical e por diversos grandes jornais, uma vez que são oferecidos, permanentemente, subsídios sobre os projetos, as votações e o comportamento dos partidos e parlamentares.

Em 1996, foi lançada a publicação Agenda Para Falar com os Poderes, um guia com contatos das principais autoridades do Poder Executivo, do Poder Legislativo e do Poder Judiciário. Desde o primeiro número, a agenda é coeditada por várias entidades filiadas ao DIAP e é o seu produto de maior circulação. Foi também em 1996 que a primeira versão da página do DIAP tornou-se disponível na Internet.

Além dos informativos mensais (Boletim e Jornal do DIAP), das publicações anuais como os "Cabeças" do Congresso Nacional e a Agenda Para Falar com os Poderes, o Departamento envia diariamente, via e-mail, a Agência DIAP, com as últimas informações sobre as atividades e acontecimentos do Congresso Nacional.

A Agência DIAP é um importante instrumento de informação e hoje é o principal veículo de comunicação entre o Departamento e as entidades filiadas. A Agência é enviada por e-mail exclusivamente às entidades filiadas, mas após o envio personalizado para os filiados, o DIAP a disponibiliza na página que mantém na Internet.

Outro produto recém lançado pelo DIAP, com acesso restrito mediante senha para as entidades filiadas, é o Sistema DIAP. O Sistema DIAP consiste em um banco de dados com informações sobre a legislação de interesse do mundo do trabalho (leis e MP's em vigor); os projetos de interesse do movimento sindical; perfil político e participação dos deputados e senadores em bancadas e frentes parlamentares; bases eleitorais referentes às eleições de 1998, e eventual acompanhamento de projetos de interesse específico de categoria profissional filiada ao DIAP.

O lançamento de livros também é uma constante. O livro Quem é Quem foi editado em 1986 e apresentava a atuação dos parlamentares sobre as matérias de interesse dos trabalhadores. Já o livro Quem Foi Quem na Constituinte, publicado em 1988, apresentava a análise da atuação dos constituintes. Em 1991, o DIAP traçou o perfil dos primeiros deputados distritais de Brasília e os apresentou no livro Quem é Quem na Câmara Distrital.

Em 1993, foi lançado o livro A Cabeça do Congresso - Quem é Quem na Revisão Constitucional. Em 1994, lançou a série anual "Os Cabeças" do Congresso Nacional, sobre a elite parlamentar, e a série AGENDA - Para Falar com os Poderes Legislativo, Executivo e Judiciário.

O DIAP publica também as séries Caderno Debate, Estudos Políticos e Estudos Técnicos. 


\section{Considerações Finais}

A partir do exposto, podemos perceber que a história do DIAP está intrinsecamente relacionada ao processo de redemocratização pelo qual passou o país.

Sua atuação na Assembléia Nacional Constituinte, no movimento de revisão da Constituição Brasileira em meados da década de 90, no impeachment do ex-presidente Collor e nas reformas constitucionais efetuadas durante o mandato do ex-presidente Fernando Henrique Cardoso, contribuiu para a consolidação democrática, através da formulação de estudos, pesquisas e do acompanhamento e avaliação da atuação dos parlamentares no Congresso Nacional.

Embora não represente interesses específicos das entidades filiadas, pois sua atuação está centrada nas matérias consensuais e interesses majoritários do movimento sindical, o DIAP traça uma estratégia de ação e orienta as entidades a agir, oferecendo inclusive cursos de treinamento em processo legislativo.

Como 10\% das entidades filiadas possuem sede em Brasília, o relacionamento entre elas e o DIAP é bastante estreito e a mobilização popular pode ser feita facilmente. Além disso, o relacionamento estreito entre as entidades e o DIAP garante uma ação conjunta mais afinada e, portanto, mais eficaz.

Desse modo, um dos princípios do DIAP continua sendo respeitado até os dias de hoje: orientar e não dirigir.

Uma das questões mais interessantes com relação ao DIAP diz respeito à sua ação propositiva. Logo após sua criação, o DIAP já mostrava seu caráter propositivo. Os Projeto Um, Dois e Três, são bons exemplos desse caráter. O Projeto Um congregava as bandeiras e lutas do movimento sindical. Já o Projeto Dois versava sobre o Poder Normativo da Justiça do Trabalho e o Projeto Três sobre a Organização Sindical.

Além desses três projetos, o DIAP ainda apresentou à Assembléia Nacional Constituinte uma Emenda Popular que dizia respeito aos direitos dos trabalhadores.

Dessa forma, podemos perceber que o DIAP não se restringe a acompanhar os poderes da República; ele também faz uma tentativa de pautar a agenda desses poderes propondo projetos e emendas populares.

Suas publicações são fontes de informação confiáveis e isso lhes confere grande legitimidade junto aos tomadores de decisão. Aliada à legitimidade, há também a visibilidade pública que as mobilizações que empreende lhe proporcionam.

Essas duas características, legitimidade e visibilidade pública, são os principais instrumentos de convencimento do DIAP. Os tomadores de deci- 
são confiam na informação que estão recebendo e, assim, pode decidir-se de maneira mais fácil, pois encontram-se pautados por estudos criteriosos e muitas vezes ousados, como a série Os Cabeças do Congresso Nacional.

Hoje, o DIAP é visto como um forte interlocutor da sociedade civil junto aos tomadores de decisão em nível federal, mostrando o ponto de vista do trabalhador e representando os seus interesses no Congresso Nacional. Porém, esse fato não garante que todas as suas demandas logrem êxito.

O lobbying no Brasil carece de um investimento de monta e uma pequena entidade como o DIAP que vive única e exclusivamente de contribuições de seus filiados jamais poderá fazer frente com igualdade a outras entidades sustentadas pelo Comércio, pela Indústria e pelos Agricultores.

Sendo assim, é o caráter informativo e não o combativo que deve ser visto como a grande arma do DIAP nessa grande luta entre trabalhadores e patrões no universo da representação de interesses no Brasil.

\section{REFERÊNCIAS}

ARAGÃO, MURILLO. Os Grupos de Pressão no Congresso Nacional: abordagem ao Papel dos Grupos no Legislativo, seus procedimentos e legislação pertinente. 1992. Dissertação (Mestrado em Ciência Política) - Faculdade de Estudos Sociais Aplicados, Universidade de Brasília, Brasília.

CARVAlHO, Maria do Carmo A. A. Participação social no Brasil Hoje. Pólis Papers, São Paulo, n. 2, 1998. Disponível em <http://www.polis.org.br〉. Acesso em: out.2004.

DIAP. Quem foi Quem na Constituinte: nas questões de interesse dos trabalhadores/DIAP. São Paulo: Cortez, 1988.

DREIFUSS, René Armand. O jogo da direita na Nova República. Petrópolis: Ed. Vozes, 1989.

FIGUEIRA, Archibaldo. Lobby: do fico à UDR. São Paulo:Ed. Sagra, 1987.

GRAZIANO, Gigi. Lobbying, troca e definição de interesses: reflexões sobre o Caso Americano. Dados, Rio de Janeiro, v. 37, n. 2, p.317-340, 1994.

GRAZIANO, Luigi. Lobbying and the Public Interest. In: ENCONTRO ANNUAL DA ANPOCS, 20., 1996, Caxambu.

MICHILES, Carlos et al. Cidadão Constituinte: a saga das emendas populares. Rio de Janeiro: Paz e Terra, 1989.

SANTOS, Roberto A. O. O Sindicato como grupo de pressão política: o caso dos trabalhadores. In: PRADO, Ney (Coord.). Direito Sindical Brasileiro. São Paulo: LTr, 1998. 
